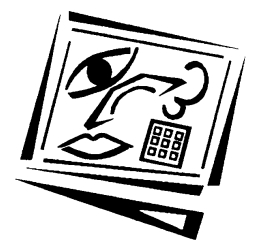

\title{
Instructional design for cross-cultural online collaboration: Grouping strategies and assignment design
}

\author{
Chun-Min Wang \\ National Hsinchu University of Education
}

\begin{abstract}
The latest networking technologies have made it easier to provide authentic learning experiences for intercultural collaboration. However, more guidance about how to conduct a successful online, cross-cultural collaboration is needed. The purpose of this study was to investigate the instructional design for forming a cross-cultural group and designing the assignments for online cross-cultural collaboration projects. By investigating two collaborative classes of college students from the United States and Taiwan, the study analysed two different grouping strategies and various types of assignments to examine the level of students' learning satisfaction. The study adopted the action research approach, and collected data from an online survey and the students' reflection essays. The findings indicate the importance of building a sense of learning community and taking advantage of integrating multimedia for assignment design. The findings also suggest that instructors should have strict requirements for communication between partners, and take advantage of Web 2.0 tools for informal communication. More details about the challenges encountered and suggestions for improvement are discussed in the article.
\end{abstract}

\section{Introduction}

Preparing college students to become global citizens with intercultural communication skills and sensitivity to cultural differences has become one of the important tasks in higher education (Bennett, 2002; Braskamp, 2008; Teng, 2005). The rationale for having global citizenship education has been addressed by education theorists, ranging from more practical perspectives that emphasise training competitive students in the global context, to more reflective perspectives that highlight the understanding of cultural differences and how to relate to others. As compiled by Evans, Ingram, Macdonald and Weber (2009), these rationales include some macro-orientations like preparing students for the global marketplace, learning for world mindedness, fostering cosmopolitan understanding, cultivating critical literacy and planetary responsibility, and encouraging deep understanding and civic action to redress global injustices.

Several learning goals associated with global citizenship education have been addressed in the literature from different perspectives. Some of the core learning goals include providing opportunities to deepen one's understanding of global systems, explore and reflect upon ones' identity and membership through a lens of world mindedness, and examine diverse beliefs, values, and world views within and across varied contexts (Evans, et al., 2009). To achieve these learning goals, scholars have developed several teaching strategies to guide the design of a global education course. For example, Pike and Selby (2000) proposed a four-dimensional model that emphasises students' inner reflection on the interdependence and interrelationship of 
time changes (past, current, and future), spaces (local and global), and issues (society, environment, races, gender, ...etc) to design and develop a course that includes global perspectives. The emphasis on promoting global citizenship education is good, but the challenge for educators is how to create a meaningful experience that can integrate as many components as possible. As suggested by Bacon and Kischner (2002), providing students with opportunities to meet new people from different cultures, and apply what they have learned in the classroom can help students to reshape their worldview and their relationship to the world. These opportunities can now be created with advanced networking technology. In this new era, more learning opportunities become possible and new teaching strategies are needed for future global citizenship education.

Beginning with email, educators have applied technology to increase cultural awareness over the past two decades (Davis, Cho \& Hagenson, 2005). These teachers believe technology can increase access to learning opportunities in this globalised educational context (Davis, 1999). Due to the consideration of time and money, it is very difficult for higher education institutions to provide opportunities for college students to go abroad for cultural experiences. Students usually get to know other cultures and expand their world views through second hand resources rather than through involvement in an authentic learning environment. As a result, taking advantage of the affordances of networking technologies that are cross borders, teachers have more opportunities to establish a cross-cultural online learning environment. Researchers have found that by adopting collaboration in the classroom, teachers can encourage higher order thinking, create reciprocating learning environment, and enhance new knowledge building (Cohen, 1994; Lai \& Law, 2006). Research also indicates that collaboration can improve students' learning performance in different settings (Rohrbeck, Ginsburg-Block, Fantuzzo \& Miller, 2003; Springer, Stanne \& Donovan, 1999), and the value of collaboration was also considered important in online learning environment as well (Jung, Choi, Lim \& Leem, 2002). When collaboration involves cross-cultural experience, it not only expands students' view of multiculturalism, but it also enhances their self-identification and empathy with different cultures (Cifuentes \& Murphy, 2000). Involving students within crosscultural teams is also an effective way to prepare students for future intercultural settings (Krishnamurthi, 2003).

Although there has been research on the effectiveness of various types of collaborations in education, only a small proportion has involved cross-cultural dimensions (Sweeney, Weaven, \& Herington, 2008). This is probably because it is not an easy task to develop a successful cross-cultural collaboration. For example, the instructor needs to overcome the problem of different time zones for synchronous communication (Murphy, 2005), and also needs to be aware of differences between groups in levels of familiarity with technology (Lajoie et al., 2006). There is the issue of language barriers as well (Teng, 2005; Wang \& Reeves, 2007). Moreover, students from different cultural backgrounds usually have different online collaborative behaviors, and the instructor needs to take these cultural differences into consideration when facilitating the online collaboration (Kim \& Bonk, 2002). It is also time consuming as the instructors need to communicate and negotiate with teachers from other countries, and it creates difficulties in grading and maintaining the platform to support collaboration (Braskamp, 2008). Although some general tips for online cross-cultural collaboration were proposed (Saphiere, 2000) such as be mindful, be comfortable with silence, encourage differing viewpoints, avoid debates, observe, and normalise 
diversity, more teaching strategies and suggestions for operating online cross-cultural collaboration in educational settings are needed.

As pointed out by Tutty \& Klein (2008), no matter whether the collaboration occurs in traditional classrooms or virtual space, the learning goals can be achieved if the teaching strategy is adopted appropriately. The only difference is that the instructor needs to consider more deeply the course content and the design of the assignment in a virtual space. The teacher is the key for the success of collaboration (Sammons, 2007), and except for complying with the capability of the technologies, teachers must develop a pedagogical framework that starts from "what it takes to learn" to challenge the development of technologies as well (Laurillard, 2009). However, there are few empirical studies that address the issues of instructional design for online crosscultural collaboration. The challenges of offering cross-cultural learning environments should not be underestimated (Braskamp, 2008). Given that the future world will be inevitably more globalised and "flat" (Friedman, 2005), promoting cross-cultural online collaboration for learning will definitely be a valuable and meaningful goal to pursue.

\section{Research context}

The present study involved 126 college students from four different classes who had not had any cross-cultural online experiences before. Two classes were from the University of Georgia in the United States, and the other two were from the National Hsinchu University of Education in Taiwan. The American students were in the College of Education and enrolled in a course called "Introduction to Computers for Teachers". Class A had 21students (3 males and 18 females), and class B had 22 students (4 males and 18 females). Although some of the American students knew a few Chinese characters, none of them could speak in Chinese. On the other hand, the Taiwanese students had taken English classes since they were in the junior high school. They had poor to moderate levels of English comprehension in reading, listening, speaking and writing. The Taiwanese students were also in the College of Education and enrolled in a course called "Introduction to Learning Technology". Class A had 41 students ( 7 males and 34 females) and class B had 42 students (9 males and 33 females). The two classes in the United States had the same instructor, as did the two in Taiwan. Before starting the project, several online meetings were conducted between the instructors via Skype to discuss the details of the collaboration. The project lasted for about three months during the fall semester in 2009.

\section{Research questions}

Given that there is a need for more knowledge about how to conduct online crosscultural collaboration and a lack of empirical studies in this area, this research was interested in the issues concerning group size and assignment design for cross-cultural collaboration. Specifically, the study had two research questions: (1) How to form a cross-cultural online collaboration group in order to achieve better learning satisfaction? and (2) How to design assignments for cross-cultural online learning collaboration in order to achieve better learning satisfaction? For the first question, the study was interested in comparing different grouping strategies in terms of the group size to see which composition can achieve better learning satisfaction. For the second question, the study categorised the assignments into two dimensions and evaluated the students' feedback on different assignments to find out what kind of assignments can achieve better learning satisfaction. 


\section{Methodology}

The study adopted the action research approach (Carr \& Kemmis, 1986): instructors plan, act, observe, and reflect on what happens during the collaboration with the intent to reconstruct and improve the instructional design. As action research usually involves practitioners in the community of practice, the instructors in the project were also the researchers. Unlike other online cross-cultural collaboration projects using learning management system such as Blackboard or WebCT, the present study adopted the popular social networking site, Facebook, as the virtual space for the collaboration. Students were asked to post their greeting messages and feedback on a specific group created for this collaboration on Facebook. There were at least two advantages of adopting Facebook for cross-cultural collaboration as addressed by Wang (2011). First of all, it was free of charge and did not require technology staff to maintain the platform. Secondly, the students could continue their friendship and connection via Facebook even after the collaboration was officially ended. In addition to Facebook, the study also used YouTube to present students' products.

\section{Research design}

In order to investigate the effect of group size, two different grouping strategies were applied to class A and class B. Based on our previous teaching experience, Taiwanese students became nervous if there were no other Taiwanese students in the same group. As a result, in the present study, each group had more than one Taiwanese student. The students in class A were paired up to form 20 groups. Each group had two Taiwanese students and one American student except for the last group which had three Taiwanese students and two American students. On the other hand, the students in the class B were paired up to form 11 groups. Each group had four Taiwanese students and two American students except for two groups which had three Taiwanese students and two American students. The reasons to pair up the students in these ways were because of the total number of the students enrolled in these classes as well as the consideration of teaching loads.

In addition to the grouping strategies, the assignments were categorised by two dimensions: Tasks and Interactions, and each dimension was divided into two subcategories. Table 1 below lists the assignments in the project.

Table 1: The design of the assignments

\begin{tabular}{|l|l|l|}
\hline \multirow{2}{*}{ Interactions } & \multicolumn{1}{|c|}{ Tasks } \\
\cline { 2 - 3 } Individual & \begin{tabular}{l}
\multicolumn{1}{|c|}{ Formal } \\
Self-introduction video, gift \\
exchange, and evaluation.
\end{tabular} & $\begin{array}{l}\text { Weekly communication (emails, } \\
\text { instant messages). }\end{array}$ \\
\hline Group & $\begin{array}{l}\text { PowerPoint game, and video } \\
\text { conference. }\end{array}$ & $\begin{array}{l}\text { Group discussion (weekly assigned), } \\
\text { and Facebook discussion. }\end{array}$ \\
\hline
\end{tabular}

The formal tasks were required and most of them were graded, and the informal tasks were encouraged but not graded. The individual interactions were the tasks completed individually, and the group interactions were the tasks completed jointly in a group. The assignments are listed below in the order of occurrence in the courses:

Photo Story self-introduction video

Each student was asked to develop a one minute video using the free Microsoft Photo Story software to introduce his/her own life. In addition to things like family, habits, 
and friends, the students were also encouraged to include something related to their own cultural heritage. All videos were then uploaded to a YouTube channel created for this project and allowed other students to comment on them.

\section{Video conference}

One synchronous online video conference using Skype was held at the beginning of the collaboration. The intention was to increase motivation for later collaboration. During the 30 minute conference the students took turns asking general questions such as favourite movie stars or songs. However, due to the 12 hour time zone difference and personal schedules, only a few American students were able to attend the conference.

Facebook discussion group

The instructors created two groups on Facebook for class A and class B individually, and divided students into small discussion groups according to the grouping strategy. The students were asked to post welcome messages and feedback to their partners' work on the Facebook discussion board.

\section{PowerPoint game}

The main assignment of this cross-cultural collaboration was to produce a PowerPoint game (Barbour, Rieber, Thomas \& Rauscher, 2009). Each group was expected to produce a PowerPoint game related to their partners' culture. For example, if the Taiwanese students wanted to develop a game related to football, they needed to consult with their American partners to know more about football. During the process of game design and development, each group was expected to interact frequently.

\section{Gift exchange}

At the end of the collaboration, each student was asked to give a small gift to their foreign partners as a gesture of goodwill. The gifts were sent to partners in an international package, and distributed at the end of the collaboration.

\section{Evaluation}

Each student was asked to fill out an online survey and write a reflection essay about their learning experience. The survey and reflection essay were the main instruments used in the study to collect perspectives from the students.

\section{Instruments}

The study used an online survey and the students' reflection essays as the primary instruments to collect data. The Likert scale five-point online survey was developed by the researchers and was reviewed by two experts to ensure content validity. The online survey had Chinese and English versions for different students, and included 21 questions that related to four categories (see the Appendix). The online survey was developed with Google Forms and was distributed at the end of the collaboration. For the reflection essays, the students were asked to reflect on their collaboration experience based on the following eight guiding questions:

1. Please describe your first impression when you know this cross-cultural collaboration.

2. Please describe your interaction with your American/Taiwanese partners.

3. What were the challenges and difficulties encountered during the interaction?

4. What can be done to avoid the challenges and difficulties mentioned above? 
5. How do you think about Facebook as the platform for this cross-cultural collaboration?

6. For the course assignments, what suggestions can you give to improve this crosscultural collaboration?

7. What suggestions can you give regarding the grouping (US-TW students)?

8. Overall, what do you learn and how do you think about this learning experience?

\section{Data analysis}

For the online survey, except for the descriptive statistics data generated from the responses, several statistical $t$-tests were conducted to compare the differences between two groups. The aim was to examine whether there were significant differences between groups in terms of students' learning satisfaction. The reflection essays were analysed by using the open coding strategy. General themes based on the guiding questions were generated from the students' essays to conceptualise the responses to the research questions. The Taiwanese students' reflections essays were analysed in Chinese, but later translated into English by the author for reporting purposes. All of the students filled out the online survey and submitted the reflection essays.

\section{Results}

\section{Photo Story self-introduction video is the favourite activity}

Photo Story was indicated as the favourite activity for both American and Taiwanese students. The students thought the Photo Story self-introduction video was an interesting and helpful assignment for them to get to know each other. As one American student commented, "I enjoyed learning about the Taiwanese culture in an interesting way. I like the Photo Story activity because I got to learn about each partner." Another student wrote, "I really enjoyed the Photo Stories. This was a fun way to be creative!" Some students even suggested creating longer videos so that they can introduce more to their partners.

The gift exchange and the real time video conference were reported as the second and third favourite activities in the project. The students were very excited to see their partners face to face online, and to receive gifts from their partners.

\section{PowerPoint game production is the least favourite activity}

PowerPoint game production was reported as the least favourite activity in the collaboration. Although the majority of the students had neutral feelings about the inputs from their foreign partners during the PowerPoint game production, four American students indicated that they were very unsatisfied. The reason given was that they had difficulty getting a timely response from their partners. Some students felt it would work better if American students created games about their own culture and Taiwanese students created games about Taiwanese culture.

\section{Language barrier and time differences are the main challenges}

The main challenge perceived during the collaboration was the language barrier. The American students could not speak and type in Chinese and the Taiwanese students had limited English comprehension. As pointed out by one Taiwanese student, "The 
most difficult thing is the language barrier. Although we can understand each other, it becomes very difficult when I want to further share the Taiwanese culture to my partner." The other student expressed her embarrassment during the communication. As she said, "Since my English is really poor, it is very difficult for me to use English to communicate with my partner. I am afraid of making mistakes, so I am unwilling to initiate the talk." Due to the low confidence in using English, the communication between the American and Taiwanese students was limited to some extent. Another main challenge was the time difference. As mentioned by one Taiwanese student, "Because of the time difference, it is difficult to find a time that we can discuss." Additionally, sometimes it took days to complete an idea exchange during the collaboration. The responses from each other were not simultaneous, and this might have lowered their motivation to communicate privately. Other issues such as lack of common interests, and different cultural background also caused difficulties for further conversations.

\section{Facebook is a good platform for cross-cultural collaboration}

The majority of the American and Taiwanese students strongly agreed that Facebook is a good platform for cross-cultural collaboration. Students could share albums, play games, and communicate easily. One American student stated, "I think Facebook is the best way to do it because we have outside motivation to check it and we're all familiar with the ins and outs of it." They also thought that Facebook was easy to use because people can receive instant updates from friends. Facebook also has some thoughtful functions such as an application that reminds people of their friends' birthdays. One Taiwanese student actually received a birthday 'Ecard' from her American partner, and she was very moved by the message as she mentioned in her reflection essay.

However, the amount of interaction varied among groups and within members of the groups. Some groups only communicated during required activities: Photo Story feedback and PowerPoint game ideas. As a result, some students complained about not having the level of interaction as they expected. For example, one of the American students pointed out, "I tried to interact with them but they did not respond like I thought they would." Other groups interacted more frequently via Facebook using the wall, viewing photographs, and using the chat feature. One American student said, "One of my partners sent me chats on Facebook quite often. She was eager to talk and discuss common likes and dislikes." Another student pointed out, "My partners were all very energetic and supportive. Every project I did they commented on and asked questions. They seemed to look through a lot of my pictures to get an idea of an American life."

\section{Students ask for more interaction}

The American students recommended having more collaboration between instructors to better organise the video conference and the timing of when students will send messages to each other. Moreover, providing more time in class for students to talk with partners and communicating weekly were also very helpful. For the suggestions from the Taiwanese students, some students recommended having partners from nearby countries in closer time zones such as South Korea, Japan, New Zealand, or Australia. Another student recommended having partners from similar cultural backgrounds to improve communication. Students felt that the assignments were appropriate, but recommended that more required discussion would be helpful. It was suggested that students be given more themed discussion topics to encourage more 
communication, and more time in class to get familiar with their partner. Taiwanese students suggested requiring more interactions between partners. Some assignments could be activities such as creating a video together or more video conferences. Encouraging communication other than simply project feedback such as allowing students to be "pen pals" was also suggested. Some Taiwanese students also suggested using other instant messages tools such as MSN or Skype to create synchronous online chatting opportunities.

\section{Class A has higher level of satisfaction than Class B}

Running the statistical $t$-tests to compare the differences between the American students in class A and class B, showed that the level of satisfaction in class A was significantly higher than class B in three survey questions: (1) I was satisfied with my private interaction (outside the course requirement) with my Taiwanese partners; (2) Overall, I was satisfied with my interaction with Taiwanese students; and (3) I was satisfied with the inputs from my Taiwanese partners during the PowerPoint game production. In other words, the American students in class A had better private interaction with their Taiwanese partners, and were more satisfied with their interaction with Taiwanese students and the inputs from them during the PowerPoint game production. For the Taiwanese students, although the students in class A reported a higher level of satisfaction in more than half of the survey questions, there was no sufficient evidence to conclude that there were significant differences between class A and class B.

\section{Smaller grouping with common interests}

Some students suggested smaller groupings would be preferred. Some Taiwanese students in class B suggested having two Taiwanese students to one American student or one Taiwanese student to one American student would be better. Other American students also felt it would be better to be paired with only one Taiwanese student. Moreover, some students suggested grouping the students by interests, and giving them the authority to choose their own partners. For example, several students suggested grouping males together and females together, so that they have more similar interests to share with each other. Some Taiwanese students also suggested having a video conference at the beginning of the collaboration to select their own partners.

\section{Cross-cultural collaboration has positive impact}

In the beginning of the collaboration, most students thought the cross-cultural project would be an interesting way to learn about peers in another culture. Of course some were unsure about how it would work out. After the collaboration, most of the participants were satisfied or very satisfied with this cross-cultural collaboration overall. One American student actually wrote, "This was my favorite class this semester!" One group even shared emails and birthday 'Ecards' during the project. Many students appreciated the opportunity to expand their world view and get to know people living in a different culture. As pointed out by one American student, "I really enjoyed it and I learned that while Taiwan and the US have many differences, there are a lot of ways in which we are alike. Plus, I made a friend in the process." Another American student said, "The experience was good because I got to expand my horizons and meet people from halfway around the world. It was a cool experience." 
Some Taiwanese students also noticed the differences in the life styles and learning attitudes. As one Taiwanese student pointed out:

\begin{abstract}
American students seem to be more active in the class and have more interaction with their teacher. Although we are about the same age, they seem to be more mature than we are. They have a clearer plan for their future than we do as well. Although they usually talk more directly, they are also kind and warm to friends.
\end{abstract}

Taiwanese students also expressed their excitement about the cultural differences such as the tradition of Halloween, parties, and college football. All of these experiences gave them a whole new perspective. A Taiwanese student stated, "This collaboration provided me the opportunity to experience foreign culture and realise how different we are." Some students expressed their satisfaction about this learning experience. As one student said, "I enjoyed gaining some insight into another culture. I enjoyed talking to my partners via Facebook and learning a little bit about their lives through the Photo Story project." Another student mentioned that "I became more open to communicating with someone I do not know and learning about their culture. I thought it was a great experience and I hope I can continue to keep in touch and learn more about them". The other student said, "This was a great learning experience and I really took away a lot from the project. I learned that although we are so far apart in distance, technology gives us the opportunity to join our two communities with great ease." Some Taiwanese students also noticed the differences related to the culture in the classroom. As one student pointed out, "From the video conference, I found they have no fear to express their thoughts in the classroom. Not like us, we are so shy to raise our hands. This is probably the differences between the West and the East."

Another interesting reaction from the Taiwanese students was that they wished to improve their English comprehension in order to better express their ideas and thoughts. In other words, this experience motivated them to improve their English. This is a good thing because college students in Taiwan usually need to pass an English comprehension test in order to graduate. Moreover, many Taiwanese students appreciated this collaboration experience because it expanded their view of the world and provided the opportunity to know friends from a different culture. Overall, students enjoyed the project in that they learned about another culture through the use of technology.

\title{
Discussion
}

\section{Grouping}

Even though the ratio of American students to Taiwanese students was the same in class $\mathrm{A}$ and class $\mathrm{B}$, the results indicated that two Taiwanese students to one American student is a better strategy than four Taiwanese students to two American students. One reason is that smaller groups create more opportunities for interaction, but a bigger group leads to social loafing among team members more easily. Especially when the team project did not clearly define everyone's duties, equitable student workloads in collaborative projects became an issue. Some strategies from the literature for dealing with social loafing can be things like clarifying roles and responsibilities, making tasks more meaningful for individuals, emphasising the importance of teamwork, limiting group numbers to the minimum number required to accomplish group goals, and requiring high levels of accountability (Piezon \& Donaldson, 2005). However, even in class A, there were some groups that did not run 
smoothly due to the lack of timely responses and language barriers. In other words, language barriers and time differences are more important issues than grouping in terms of causes of low motivation in a cross-cultural collaboration context. Thus, in addition to reducing the group size, focusing on facilitating communication and reducing the impact of language barriers should be the first priority.

Secondly, the students' suggestions of holding a video conference before pairing up students and grouping partners by interests indicate their hope to form a learning community. They were eager to see their partners and would like to exchange thoughts more deeply. Reflecting on the students' feedback, the media used in the project such as self-introduction video and video conference is an ideal way to increase the social presence and the sense of community among participants. The problem, as will be further discussed in the assignment section, was the requirements of participation. Many students only fulfilled the basic requirement of interaction, and did not go further to maintain the sense of a learning community. As concluded by Chang and Lim (2002), using media to increase social presence has a positive effect on the social and response processes of learning in cross-cultural asynchronous online learning setting. The present study confirms that conclusion and indicates that more strict requirements of communication are needed to maintain the sense of a learning community in cross-cultural collaboration. An encouraging finding from Teng's (2005) study was that she found that improving the development of a learning community can reduce Taiwanese students' apprehension in communicating in English. Thus, it is crucial to guide the processes of forming a group and provide strict requirements for participation in cross-cultural collaboration project.

Another issue related to group interaction is cultural differences. Although researchers have identified cultural differences among students from different countries and reminded us to take caution during the cross-cultural project (Chang \& Lim, 2002; Kim \& Bonk, 2002), these cultural differences seemed to be the best learning materials for the students to explore. Students in the study were excited to find out the differences between each other. One student even said that she liked the cultural differences and the challenges, because that made the collaboration more interesting. As a result, once there were no cultural conflicts in terms of the assignments and teaching strategies between the instructors, any other cultural differences or conflicts that happened during the collaboration are good resources for the students to experience. The key point is to let the students reflect on the whole processes and gain intercultural knowledge through this experience. As in the global education model proposed by Pike and Selby (2000), the inner dimension that emphasises the reflection part of the learning experience should be the most important. Holding an orientation regarding cultural differences in the beginning of the collaboration does help, but letting the students experience the differences and then holding a discussion at the end of the collaboration is even more helpful.

\section{Assignments}

Several findings were revealed from the results of the study. First of all, the Photo Story self-introduction video, the gift exchange, and the real time video conference were the three favourite activities. For the gift exchange activity, it is understandable because most people like presents and surprises. If the mailing costs are not a problem, the study recommends having this activity in any cross-cultural collaboration project. As for the self-introduction video and the real time video conference, it implied that the students like to view pictures, watch videos, and interact in real time situations. Based 
on the findings, the students also seemed to become acquainted with their partners through these media. As expressed by one Taiwanese student, she did not have much communication with her American partner on Facebook, but she noticed from the videos that American students are more friend-centred rather than family-centred in comparison to Taiwanese students. The finding corresponds to what Teng (2005) found in her study that incorporating virtual tours of local scenes and students' life can also be used to enhance the cultural exchange. As a result, using multimedia could be a good strategy to lower the pressure of language barriers, increase learning motivation, and also exchange cultural understanding in cross-cultural collaboration.

Secondly, unfortunately the PowerPoint game production turned out to be the least favourite activity in the collaboration. The failure can be contributed to the poor communication between partners and the assignment design. The poor communication between partners was caused by the late responses and language barriers. The late responses were due to the 12 hour time difference and to the students' not checking and responding to messages regularly. The students were asked to send a greeting message to their partners and provide feedback on the selfintroduction video, but beyond that any communication was only encouraged. The time and frequency of communication between partners depended on how fast they completed the PowerPoint game production. No wonder some students suggested having more time to talk with partners and requiring more discussions weekly. Thus, the study suggests classifying every activity as formal, which means every activity is required and graded. Based on the results, it is clear that most students would not interact actively unless they were required to do so. Expecting the students to interact automatically is more likely to end up with poor communication between partners.

As for the design of assignment, the main problem was that the PowerPoint game production could be completed without the assistance from partners. The students can produce the game with information found on the Internet even though they got feedback and suggestions from their foreign partners. Thus, a better design of the cross-cultural project is that each student from both countries should contribute to a part of the whole product. As suggested by one student, they can produce a video together. In response to this suggestion, the author initiated another cross-cultural collaboration in the year of 2010 that asked students to create a VoiceThread (http: / voicethread.com/) video instead. The outcomes were better, but the downside was that the Internet speed was too slow for Taiwanese students to access the website. After reflecting on these experimentations, three guidelines for designing crosscultural collaboration assignments are: (1) choose easy to access multimedia tools (Internet speed and cost factor); (2) design simple but meaningful collaborative tasks: and (3) prepare alternative solutions if the cross-cultural collaboration does not run smoothly.

Finally, to reflect on the two dimensions, tasks and interactions, embedded in the design of the assignments, the results indicate that the success of the informal tasks is the foundation for the success of the formal tasks. Although the study suggests that there should be no informal tasks and every activity should be required during the collaboration, the indication above showed that when students are familiar with each other they are more likely to collaborate successfully in a group project. This is similar to Lim's (2004) findings that learners are more likely to be engaged in the learning process when familiarity is developed. This also echoes the importance of building a learning community as discussed previously. Moreover, as suggested by the students, 
allowing and providing other media for private interaction was necessary. Although the study suggests that the informal assignments are not appropriate, the instructors should still support any possible channel that can facilitate informal communication between partners.

\section{Facebook}

The results of the study showed that using Facebook as the virtual space for crosscultural collaboration is acceptable and feasible. Corresponding to what was found in the present study, Aoki and Kimura (2009) also agreed that Facebook was a good site for intercultural language learning, because it has great potential to provide authentic means of communicating with native speakers in an easily accessible manner. Facebook as a universal social networking site can not only support different languages, but also has rich features that continue to evolve. Additionally, different media formats such as photos, videos, and outside links can also be easily integrated into the messages. Taking advantage of these characteristics of Facebook, Raja Hussain and Ng (2010) suggested that with some scaffoldings from the instructor, Facebook can actually be applied as an e-portfolio platform for teaching. However, given that more and more video games have been developed and integrated into Facebook, one concern raised from this experience is that how to regulate students to concentrate on their team project. Students were very easily to be distracted by the video games such as Farmville on Facebook during class.

There are some potential negative effects, such as teachers may lose their image of professionalism or students may experience a fear that information about them on Facebook could negatively influence the teachers' perceptions of them (Mazer, Murphy \& Simonds, 2007). Researchers were also interested in finding out what are appropriate behaviours between students and teachers on Facebook. For example, Young (2009) discussed the issue of adding friends. Should the teacher invite the students to be friends and vice versa? Furthermore, the privacy issue is another concern about using Facebook in education. The instructor may not feel comfortable sharing personal photos with the students. As Munoz \& Towner (2009) reminded, maintaining a level of professionalism that does not cross the boundary of the teacher-student relationship is important. Thus, they suggested teachers should have an additional Facebook profile for professional use only, and this profile should be entirely separate to their social/personal profile.

\section{Conclusion}

As the needs for global citizenship education keep growing, more guidelines about how to conduct cross-cultural collaboration with new networking technologies are necessary. In this study, the challenges encountered during cross-cultural collaboration and the suggestions of improvements are discussed. To make it easier for the readers, the major points from this study are highlighted below:

\section{Develop a sense of learning community}

A sense of learning community can increase learning motivation and confidence in using English. This can be achieved through careful matching of partners and controlling group size. The present study found that smaller group size is better in cross-cultural setting, and two non-native English speakers grouping with one English native speaker is appropriate. With clear and strict requirements, students can overcome the late responses and poor communication more easily. 
2. Design multimedia assignments

Assignments involving multimedia such as video and photos can not only increase social presence in the online community, but can also increase students' learning motivation. Additionally, allowing different formats of media will also increase the private interaction among students.

3. Cherish the differences

Although language barriers were identified as the major challenge, this experience turned out to be the impetus for Taiwanese students to improve their English comprehension. Nevertheless, some assistance such as hiring bilingual teaching assistants can certainly be helpful. The cultural differences became the best learning materials for student to explore during the collaboration. Holding a reflection session at the end could help students to internalise the intercultural knowledge learned from the collaboration.

4. Adopt Web 2.0 applications

Finally, as Churchill (2009) proposed, Web 2.0 applications have great potential to improve teaching and learning; the present study has proved that adopting Facebook as the virtual platform for cross-cultural collaboration is appropriate and feasible. However, as the features of Facebook and other Web 2.0 applications continue to evolve; different strategies of using these applications in cross-cultural collaboration will need to be adjusted constantly.

The study serves as a good start to explore better teaching strategies for online crosscultural collaboration. Taking from the perspectives of grouping and assignment design, the study explored several issues and identified some possible suggestions. Future studies can investigate the appropriate strategies of regulating the interaction among students from different cultures, as well as the strategies to evaluate their performances. Additionally, it will be helpful to explore the teacher-student relationship, online behaviors, and privacy issues on Facebook as well as other Web 2.0 applications in cross-cultural context in order to design a better learning community. Developing new strategies and evaluation methods to integrate multimedia into the design of cross-cultural assignments will also be useful.

\section{Acknowledgment}

The research was funded by the National Science Council in Taiwan (NSC 98-2511-S134-005). The author would like to thank Gretchen Bourdeau Thomas and Jinn-Wei Tsao at the University of Georgia for their help in conducting the collaboration. The author would also like to thank the editor Dr Roger Atkinson and the anonymous reviewers for their valued feedback.

\section{References}

Aoki, K. \& Kimura, M. (2009). Telecollaboration 2.0: Using Facebook for intercultural exchange. Paper presented at the World Conference on Educational Multimedia, Hypermedia and Telecommunications 2009, Honolulu, HI, USA.

Bacon, N. A. \& Kischner, G. A. (2002). Shaping global classrooms. Educational Leadership, 60(2), 48-51.

Barbour, M., Rieber, L. P., Thomas, G. \& Rauscher, D. (2009). Homemade PowerPoint games: A constructionist alternative to WebQuests. TechTrends, 53(5), 54-59. 
Bennett, C. I. (2002). Comprehensive multicultural education: Theory and practice (5 ed.). Boston: Allyn \& Bacon.

Braskamp, L. A. (2008). Developing global citizens. Journal of College E Character, X(1). http: / / journals.naspa.org / cgi/ viewcontent.cgi?article=1058\&context=jcc

Carr, W. \& Kemmis, S. (1986). Becoming critical: Education, knowledge, and action research. London, Philadelphia, PA: Falmer Press.

Chang, T.-T. \& Lim, J. (2002). Cross-cultural communication and social presence in asynchronous learning processes. e-Service Journal, 1(3), 83-105.

Churchill, D. (2009). Educational applications of Web 2.0: Using blogs to support teaching and learning. British Journal of Educational Technology, 40(1), 179-183.

Cifuentes, L. \& Murphy, K. L. (2000). Promoting multicultural understanding and positive selfconcept through a distance learning community: Cultural connections. Educational Technology Research \& Development, 48(1), 69-83.

Cohen, E. G. (1994). Designing groupwork: Strategies for the heterogeneous classroom (2nd ed.). New York: Teachers College, Columbia University.

Davis, N. E. (1999). The globalization of education through teacher education with new technologies: A review informed by research through teacher education with new technologies. Educational Technology Review, 1(12), 8-12.

Davis, N. E., Cho, M. O. \& Hagenson, L. (2005). Editorial: Intercultural competence and the role of technology in teacher education. Contemporary Issues in Technology and Teacher Education, $4(4), 384-394$.

Evans, M., Ingram, L. A., Macdonald, A. \& Weber, N. (2009). Mapping the "global dimension" of citizenship education in Canada: The complex interplay of theory, practice and context. Citizenship Teaching and Learning, 5(2), 17-34. http: / / www.citized.info/pdf/eJournal/journal\%20website.pdf

Friedman, T. L. (2005). The world is flat: A brief history of the twenty-first century (1st ed.). New York: Farrar Straus and Giroux.

Jung, I., Choi, S., Lim, C. \& Leem, J. (2002). Effects of different types of interaction on learning achievement, satisfaction and participation in web-based instruction. Innovations in Education $\mathcal{E}$ Teaching International, 39(2), 153-162.

Kim, K.-J. \& Bonk, C. J. (2002). Cross-cultural comparisons of online collaboration. Journal of Computer-Mediated Communication, 8(1). http:/ / jcmc.indiana.edu/vol8/issue1/ kimandbonk.html

Krishnamurthi, M. (2003). Assessing multicultural initiatives in higher education institutions. Assessment $\mathcal{E}$ Evaluation in Higher Education, 28(3), 263-277.

Lai, M. \& Law, N. (2006). Peer scaffolding of knowledge building through collaborative groups with differential learning experiences. Journal of Educational Computing Research, 35(2), 123-144.

Lajoie, S., Garcia, B., Berdugo, G., Márquez, L., Espíndola, S. \& Nakamura, C. (2006). The creation of virtual and face-to-face learning communities: An international collaboration experience. Journal of Educational Computing Research, 35(2), 163-180.

Laurillard, D. (2009). The pedagogical challenges to collaborative technologies. International Journal of Computer-Supported Collaborative Learning, 4(1), 5-20. [preprint verified 11 Apr 2011] http: / / ijcscl.org / download.php?file=laurillard_4_1.pdf\&path=_preprints / volume4_issue1

Lim, C. P. (2004). Engaging learners in online learning environments. Tech Trends, 48(4), 16-23. 
Mazer, J. P., Murphy, R. E. \& Simonds, C. J. (2007). I'll see you on "Facebook": The effects of computer-mediated teacher self disclosure on student motivation, affective learning, and classroom climate. Communication Education, 56(1), 1-17.

Munoz, C. \& Towner, T. (2009). Opening Facebook: How to use Facebook in the college classroom. Paper presented at the Society for Information Technology \& Teacher Education International Conference 2009, Charleston, SC, USA.

Murphy, E. (2005). Issues in the adoption of broadband-enabled learning. British Journal of Educational Technology, 36(3), 525-536.

Piezon, S. L. \& Donaldson, R. L. (2005). Online groups and social loafing: Understanding student-group interactions. Online Journal of Distance Learning Administration, 8(4), [viewed 5 Apr 2011] http:/ / www.westga.edu/ distance/ ojdla/winter84/ piezon84.htm

Pike, G. \& Selby, D. (2000). In the global classroom 2. Toronto: Pippin.

Raja Hussain, R. M. \& Ng, H. Z. (2010). A case-study: The adoption, adaptation and transformation of Facebook as eportfolio in higher education. Paper presented at the Global Learn Asia Pacific 2010, Penang, Malaysia.

Rohrbeck, C. A., Ginsburg-Block, M. D., Fantuzzo, J. W. \& Miller, T. R. (2003). Peer-assisted learning interventions with elementary school students: A meta-analytic review. Journal of Educational Psychology, 95(2), 240-257.

Sammons, M. (2007). Collaborative interaction. In M. G. Moore (Ed.), Handbook of distance education (2nd ed., pp. 311-321). Mahwah, NJ: L. Erlbaum Associates.

Saphiere, D. H. (2000). Online cross-cultural collaboration. Training \& Development, 54(10), 71-72.

Springer, L., Stanne, M. E. \& Donovan, S. S. (1999). Effects of small-group learning on undergraduates in science, mathematics, engineering, and technology: A meta-analysis. Review of Educational Research, 69(1), 21-51.

Sweeney, A., Weaven, S. \& Herington, C. (2008). Multicultural influences on group learning: A qualitative higher education study. Assessment E Evaluation in Higher Education, 33(2), 119-132.

Teng, L. Y.-W. (2005). A cross-cultural communication experience at a higher education institution in Taiwan. Journal of Intercultural Communication, 10. http:/ / www.immi.se/intercultural or http:/ / www.immi.se/intercultural/nr10/teng.htm

Tutty, J. \& Klein, J. (2008). Computer-mediated instruction: A comparison of online and face-toface collaboration. Educational Technology Research E Development, 56(2), 101-124.

Wang, C. M. (2011). Take the easy way: Facebook for cross-cultural collaboration. In A. Edmundson (Ed.), Cases on globalized and culturally appropriate e-learning: Challenges and solutions. Hershey, PA: IGI Global.

Wang, C. M. \& Reeves, T. C. (2007). Synchronous online learning experiences: The perspectives of international students from Taiwan. Educational Media International, 44(4), 339-356.

Young, J. R. (2009). How not to lose face on Facebook, for professors. Chronicle of Higher Education, 55(22), A1-A13. 


\section{Appendix: Cross-culturally online collaboration satisfaction survey}

\section{A. Facebook interaction}

1. Facebook is a good platform for cross-cultural collaboration with Taiwanese students.

2. My Taiwanese partners showed their motivation to interact via the Facebook.

3. I was motivated to interact with my Taiwanese partners via the Facebook.

4. I was satisfied with my interaction with my Taiwanese partners.

5. Overall, I was satisfied with the activities on the Facebook.

\section{B. Partner interaction}

6. I was satisfied with my interaction with my Taiwanese partners.

7. I was satisfied with my private interaction (outside the course requirement) with my Taiwanese partners.

8. Overall, I was satisfied with my interaction with Taiwanese students (and American partner).

\section{Course assignments}

9. I was satisfied with the photo story activity.

10 I was satisfied with the inputs from my Taiwanese partners during the PPT Game production.

11. I was satisfied with my feedback to my Taiwanese partners.

12. I was satisfied with my feedback to my American classmates.

13. I was excited about the gift exchange activity for this cross-cultural collaboration.

14. Please select your favorite activity during this collaboration (select only one item): _ Photo Story; _ Facebook interaction; _ PPT Game; _ Video conference; _ Gift exchange; Private interaction;__Giving feedback; _ Other______ (Please specify)

15. Please select your less favorite activity during this collaboration (select only one item): _ Photo Story; _ Facebook interaction;__PPT Game; _ Video conference; _ Gift exchange; _ Private interaction; _ Giving feedback; _ Other (Please specify)

\section{Overall experience}

16. Overall, I was satisfied with my performance in this cross-cultural collaboration.

17. Overall, I was satisfied with the assignments in this cross-cultural collaboration.

18. Overall, I was satisfied with my team arrangement in this cross-cultural collaboration.

19. Overall, I was satisfied with the instruction and guidance in this cross-cultural collaboration.

20. Overall, I was satisfied with this cross-cultural collaboration.

21. Any other suggestions or comments (more thoughts can be addressed in the reflection essay)?

Author: Dr Chun-Min Wang, Assistant Professor

Department of Education, National Hsinchu University of Education

No. 521 Nanda Rd. Hsinchu, Taiwan 300

Email: cwang@mail.nhcue.edu.tw Web: http:/ / www.nhcue.edu.tw/ cwang

Please cite as: Wang, C.-M. (2011). Instructional design for cross-cultural online collaboration: Grouping strategies and assignment design. Australasian Journal of Educational Technology, 27(2), 243-258.

http: / / www.ascilite.org.au/ajet/ajet27/wang.html 